\title{
THE EFFECT OF DURATION OF ACETYLCHOLINE- ESTERASE INHIBITOR ON MMSE, CDT AND BARTHEL INDEX SCORING ON PATIENTS WITH VASCULAR DEMENSIA
}

\author{
Sri Budhi Rianawati ${ }^{1}$, Ria Damayanti ${ }^{1}$, Harun Al Rasyid ${ }^{2}$, Nyoman Artha Megayasa $^{1}$ \\ Correspondence: arthamail@gmail.com \\ ${ }^{I}$ Department of Neurology Faculty of Medicine Brawijaya University, Malang, Indonesia. \\ ${ }^{2}$ Division of Public Health Sciences Faculty of Medicine Brawijaya University, Malang, Indonesia
}

\begin{abstract}
Article History:
Received: September 23, 2020

Accepted: April 21, 2021

Published: July 1, 2021

\section{Cite this as:}

Rianawati SB, Damayanti $R$, Rasyid HA, Megayasa NA. The effect of duration of acetylcholine-esterase inhibitor on mmse, cdt and barthel index scoring on patients with vascular demensia. Malang Neurology Journal; 2021.7: 104-108. http://dx.doi.org/10.21776/ub.mnj .2021.007.02.4
\end{abstract}

\section{ABSTRACT}

Background: Vascular dementia is a cognitive decline with functional deterioration caused by cerebrovascular disease. It is the second leading cause of dementia. A number of screening questionnaires and models have been developed to help in assessing cognitive function and activity daily living (ADL) in patients with dementia. Mini Mental State Examination (MMSE), Clock Drawing Test (CDT) and Barthel Index are instruments to evaluate cognitive function and ADL of vascular dementia patients.

Objective: To determine the role of achetylcholine-esterase inhibitor therapy on cognitive function and ADL in patients with vascular dementia in Saiful Anwar General Hospital.

Methods: This study is an analytical study assessing the improvement of cognitive function and ADL of patients with vascular dementia after administration of acethylcholine-esterase inhibitor by assessing the MMSE, CDT and Barthel Index scoring in 1, 3, 6 and 12 month period consecutively.

Results: From 15 study subjects, individuals who have been given treatment for 12 months consecutively have the highest increase in MMSE and CDT whilst for Barthel Index has shown highest improvement in one month period.

Conclusion: The administration of acetylcholine-esterase inhibitor drugs has the potential to improve and maintain cognitive function and improve ADL. The limited number of study subjects and the many confounding factors that we did not evaluate were the drawbacks of this study. The results of this study cannot be generalized to all patients with vascular dementia and only apply to 15 patients who were the subjects of this study.

Keywords: Vascular Dementia, MMSE, CDT, Barthel Index, Acetylcholine-esterase Inhibitor

\section{Introduction}

Dementia is one of the most common diseases in old age. According to WHO, dementia is a neurodegenerative symptom that can arise due to chronic and progressive disorders accompanied by multiple disorders of noble functions such as calculation, learning capacity, language, and decision making. In dementia awareness is not compromised. Impaired cognitive function is usually accompanied by deterioration of emotional, behavioral and motivation control. This syndrome occurs in Alzheimer's disease, in cerebrovascular disease, and in other conditions that primarily or secondary to the brain. ${ }^{1-3}$

Stroke in old age is something that is often encountered. The link between dementia and stroke is complex. The second most common cause of dementia is cerebrovascular disease. Apart from causing focal neurological deficits, stroke is also associated with dementia. Some stroke patients will develop dementia. It is estimated that about $25 \%$ of stroke sufferers can experience a decline in cognitive abilities to the level of dementia. Post-acute ischemic stroke dementia affects the length of survival after acute ischemic stroke and has a significant effect on prognosis. ${ }^{4,5}$

Vascular dementia is a cognitive decline and functional deterioration caused by cerebrovascular disease, usually hemorrhagic and ischemic stroke, also caused by ischemic substance disease or a sequence of hypotension or hypoxia. Vascular dementia is the second most common cause of dementia (20-25\%) after Alzheimer's disease (60-70\%). The reported prevalence of stroke patients with vascular dementia or post-stroke dementia ranges from 16 to $48 \%$. Post-acute ischemic stroke dementia affects the length of survival after acute ischemic stroke and the prognosis. ${ }^{2,6,7}$

A number of screening questionnaires and clinical screening models have been developed to help assess cognitive function in patients with dementia. The Mini Mental State Examination (MMSE) which was developed in 1975 is the instrument used to measure the degree of cognitive impairment, the Clock Drawing Test (CDT) which measures the cognitive function and visuospatial abilities of the patient and the Barthel Index is an 
examination to determine the level of patient independence in daily activities. ${ }^{7-12}$

This study was made with the aim of knowing the role of achetylcolinesterase inhibitor on the MMSE, CDT and Barthel Index scoring values in patients with vascular dementia at Saiful Anwar Hospital in the 2017-2019 period.

\section{Methods}

\section{Research design}

This study is an analytical study assessing the improvement of cognitive function and ADL of patients with Vascular Dementia after administration of Acethylcholine Esterase Inhibitor by assessing the MMSE, CDT and Barthel Index scoring. The increase in this value will be analyzed statistically so that the optimal term value is obtained in administering pharmacotherapy. The study design used was a retrospective cohort.

\section{Place and Time of Research}

This research was conducted at the Neurology Memory Polyclinic in Saiful Anwar Hospital, Malang, Indonesia. Sampling was in the form of medical records from 1 January 2017 - 31 December 2019 in Saiful Anwar Hospital, Malang, Indonesia.

The population in this study were patients diagnosed with Vascular Dementia who were treated at the Neurology Memory Clinic, Saiful Anwar Hospital Malang. The sample in this study were patients who visited the Neurology Memory Polyclinic at Saiful Anwar Hospital Malang in the period of 1 January 2017 - 31 December 2019.

\section{Subjects}

In the period of 1 January 2017 - 31 December 2019, there were 78 patients seeking treatment at the Neurology Memory Clinic, Saiful Anwar Hospital Malang. Based on the total sampling technique, 34 patients were diagnosed with vascular dementia. However, after being classified into inclusion and exclusion criteria, total of 15 subjects were obtained.

The sampling method used was total sampling where the researcher takes all the population into a sample. This technique is used when the population is limited.

\section{Inclusion Criteria}

Patients who came to visit the Neurology Memory Clinic, Saiful Anwar Hospital Malang and also diagnosed with Vascular Dementia who received regular Acetylcholineesterase inhibitor therapy from Neurology Memory Clinic, Saiful Anwar Hospital Malang on January 1, 2017-31 December 2019. In addition, the diagnose of vascular dementia was based on the Hachinski ischemic score. Patients also need to be routinely controlled to the Neurology Memory Clinic, Saiful Anwar Hospital Malang on the $1 \mathrm{st}, 3 \mathrm{rd}$, 6th, and 12 th months with a predetermined interval of observation time at each control time.

\section{Exclusion Criteria}

1. Patients with autoimmune diseases, brain infections, or malignancy

2. Patients who do not routinely visit the Neurology Memory Clinic, Saiful Anwar Hospital Malang based on a grace period of observation.

\section{Research Data Collection Procedures}

The research data were taken from the patient's medical records starting from gender, age, patient clinical and cognitive function assessment which was done using MMSE, CDT and Barthel Index tools. The patient will then be classified into vascular dementia based on the Hachinski ischemic score.

The data obtained in this study are the MMSE, CDT, and Barthell Index scores at 0, 1, 3, 6, and 12 months respectively with a numerical data scale.

\section{Pairwise Comparison Test}

In the pairwise comparison test, the Friedman test was performed. This test is used to compare the mean score of MMSE, CDT and Barthel Index in each time unit. The purpose of this test was to prove the effect of acetylcholinesterase inhibitor on MMSE, CDT and Barthel index scores. The difference was considered significant or significant if the $\mathrm{p}$ value was $<0.05$. All data analysis calculations used the SPSS 25 software tool.

\section{Results}

After this research was carried out, the number of patients who were the subjects of the study were 15 people. After collecting data on age, gender, education, risk factors, the following characteristics were obtained (Table 1).

\begin{tabular}{|c|c|c|}
\hline Characteristics & $\begin{array}{c}\text { Total } \\
\text { (Subjects) }\end{array}$ & Percentage (\%) \\
\hline \multicolumn{3}{|l|}{ Age } \\
\hline$<60$ years old & 10 & 66,67 \\
\hline $60-74$ years old & 4 & 26,67 \\
\hline$>74$ years old & 1 & 6,70 \\
\hline \multicolumn{3}{|l|}{ Gender } \\
\hline Men & 8 & 53,33 \\
\hline Women & 7 & 46,67 \\
\hline \multicolumn{3}{|l|}{ Education } \\
\hline No Education & 1 & 6,70 \\
\hline Primary School & 3 & 20,00 \\
\hline $\begin{array}{l}\text { Secondary } \\
\text { School }\end{array}$ & 3 & 20,00 \\
\hline High School & 4 & 26,68 \\
\hline $\begin{array}{l}\text { College or } \\
\text { University Level }\end{array}$ & 4 & 26,67 \\
\hline \multicolumn{3}{|l|}{ Stroke History } \\
\hline $\begin{array}{l}\text { Thrombotic } \\
\text { Stroke }\end{array}$ & 8 & 53,33 \\
\hline $\begin{array}{l}\text { Hemorrhagic } \\
\text { Stroke }\end{array}$ & 5 & 33,33 \\
\hline Unknown & 2 & 13,33 \\
\hline \multicolumn{3}{|l|}{ Other Risk Factors } \\
\hline $\begin{array}{l}\text { Diabetes Mellitus } \\
(\mathrm{DM})\end{array}$ & 3 & 20,00 \\
\hline $\begin{array}{l}\text { Hipertension } \\
(\mathrm{HT})\end{array}$ & 6 & 40,00 \\
\hline $\mathrm{DM}+\mathrm{HT}$ & 1 & 6,70 \\
\hline Dyslipidemia & 2 & 13,33 \\
\hline Unknown & 3 & 20,00 \\
\hline
\end{tabular}

In this study, patients with vascular dementia who underwent treatment at Neurology Memory Clinic, Saiful Anwar Hospital Malang based on the gender were mostly male, amounting to 8 patients $(53.33 \%)$ and female, amounting to 7 patients $(46.67 \%)$. The largest age range 
was less than 60 years as many as 10 people (66.67\%) followed by the age range of 60-74 years as many as 4 people $(26.67 \%)$.

Based on the level of education in this study, it was found that 1 patient did not go to school, 3 patients had primary education, 3 patients were at secondary education level, 4 patients had higher education level and 4 patients were with college or university level of education. The prevalence of vascular dementia in the population with higher education levels is more likely to suffer from vascular dementia. This, however, does not reflect objectively, because the number of patients who come to the Neurology Memory Clinic, Saiful Anwar Hospital Malang does not represent the number of patients with vascular dementia in one place and the number of study subjects is also limited. High likelihood, vascular dementia patients with less education are less likely to have the right education to go for treatment at Neurology Memory Clinic, Saiful Anwar Hospital Malang.

Research on the effect of the duration of acethylcolineesterase inhibitor administration on the MMSE, CDT, and Barthell Index scoring of vascular dementia patients at the Neurology Memory Clinic, Saiful Anwar Hospital Malang was carried out in a retrospective cohort analysis by looking at the results of existing medical records in the period of 1 January 2017 to 31 December 2019. The sample was carried out by using total sampling technique in patients diagnosed with vascular dementia who met the inclusion criteria at the Neurology Memory Clinic, Saiful Anwar Hospital Malang based on a predetermined time period. Observation data were taken on the administration of acethylcoline-esterase inhibitor therapy at months $1,3,6$, and 12 .

\section{Data Analysis}

\section{Pairwise Comparison Test MMSE Score}

In the MMSE score data, the comparative test data was analyzed, namely the paired comparison test between the scores at 0, 2 weeks, 1 month, 3 months, 6 months and 12 months to see improvements in MMSE scores in vascular dementia patients who were given acetylcholine-esterase inhibitor drug therapy. The results of the Friedman test showed significant results in the comparison of the drug administration period with $\mathrm{p} \leq 0.001$ and Chi Square 33.082. The chi square value for df 5 with $p<0.05$ is 11.070. Thus, Chi Square was $33.082>11.070$, so a significant increase in the MMSE score was obtained from the administration of drug therapy. In the mean rank results obtained the highest score of 5.27 in the 12 month group, which shows the highest score increase was at month 12 after giving therapy.

Table 2. The mean value and the results of the Friedman MMSE test on the research subject $(\mathrm{N}=15)$

\begin{tabular}{cccc}
\hline Observational & $\begin{array}{c}\text { Mean Value } \\
\text { MMSE } \pm \text { SD }\end{array}$ & $\begin{array}{c}\text { Friedman } \\
\text { Test }\end{array}$ & Mean Rank \\
\hline Month 0 & $16,07 \pm 8.09$ & & 2,03 \\
Week 2 & $18,00 \pm 6.44$ & & 2,73 \\
Month 1 & $19,27 \pm 6,46$ & $\mathrm{p} \leq 0,001$ & 2,83 \\
Month 3 & $21,33 \pm 5,58$ & & 3,63 \\
Month 6 & $22,20 \pm 4,87$ & & 4,50 \\
Month 12 & $23,33 \pm 6,30$ & & 5,27 \\
\hline
\end{tabular}

\section{Pairwise Comparison Test CDT Score}

In the CDT score data, the comparative test data was analyzed, namely the pairwise comparison test between the scores at 0,2 weeks, 1 month, 3 months, 6 months and 12 months to see the improvement in CDT scores in vascular dementia patients who were given therapy with acetylcholine-esterase. inhibitor. The results of the Friedman test showed significant results in the comparison of the period of drug administration with $p \leq 0.001$ and Chi Square 30.759 . The chi square value for df 5 with $p<0.05$ is 11.070. Thus, Chi Square 30,759> 11,070, so a significant increase in CDT score was obtained from drug therapy. In the mean rank results, the highest score was 4.70 in the 12 month group, which shows the highest score increase was at month 12 after giving therapy.

Table 3. The mean value and the results of the Friedman CDT test on the research subject $(\mathrm{N}=15)$

\begin{tabular}{cccc}
\hline Observational & $\begin{array}{c}\text { Mean Value CDT } \pm \\
\text { SD }\end{array}$ & $\begin{array}{c}\text { Friedman } \\
\text { Test }\end{array}$ & $\begin{array}{c}\text { Mean } \\
\text { Rank }\end{array}$ \\
\hline Month 0 & $1,73 \pm 1.44$ & & 2,27 \\
Week 2 & $2,07 \pm 1.53$ & & 2,80 \\
Month 1 & $2,33 \pm 1,45$ & $\mathrm{p} \leq 0,001$ & 3,20 \\
Month 3 & $2,73 \pm 1,22$ & & 4,20 \\
Month 6 & $2,67 \pm 1,40$ & & 3,83 \\
Month 12 & $3,07 \pm 1,28$ & & 4,70 \\
\hline
\end{tabular}

\section{Pairwise Comparison Test Barthel Index}

In the Barthel Index score data, the comparison test data was analyzed, namely the pairwise comparison test between the scores at 0,2 weeks, 1 month, 3 months, 6 months and 12 months to see improvements in Barthel Index scores in vascular dementia patients who were given therapy with acetylcholine-esterase inhibitors. In the Friedman test results obtained significant results in the comparison of the period of drug administration with $\mathrm{p}=0.019$ and Chi Square 13.500. The chi square value for df 5 with $\mathrm{p}<0.05$ is 11.070. Thus, Chi Square 13,500> 11,070, so the significant increase in Barthell Index score is obtained from the administration of drug therapy. In the mean rank results, the highest score was 3.90 in the 1 month group, which shows the highest score increase was at month 1 after giving therapy.

Table 4. The mean value and the results of the Friedman Barthel Index test on the research subject $(\mathrm{N}=15)$

\begin{tabular}{cccc}
\hline Observational & $\begin{array}{c}\text { Mean Value Barthel } \\
\text { Index } \pm \text { SD }\end{array}$ & $\begin{array}{c}\text { Friedman } \\
\text { Test }\end{array}$ & $\begin{array}{c}\text { Mean } \\
\text { Rank }\end{array}$ \\
\hline Month 0 & $85,33 \pm 21,91$ & & 2,90 \\
Week 2 & $90,67 \pm 16,46$ & & 3,30 \\
Month 1 & $92,00 \pm 16,67$ & $\mathrm{p}=0,019$ & 3,90 \\
Month 3 & $91,67 \pm 16,65$ & & 3,77 \\
Month 6 & $88,33 \pm 22,57$ & & 3,37 \\
Month 12 & $91,67 \pm 16,65$ & & 3,77 \\
\hline
\end{tabular}

\section{Discussion}

The incidence of cerebrovascular disease worldwide is one of the most common causes of cognitive impairment, even higher than Alzheimer's disease. The most common and frequently encountered type of cerebrovascular disease is ischemic stroke or cerebral ischemic damage. Old age is still the strongest risk factor for stroke and other cerebrovascular diseases. Cerebrovascular disease also includes changes in the cerebral or systemic arteriosclerosis or both. Whereas early or minor vascular changes may not be recognized or clinically recognized, they are only 
incidentally found on radiological features in white matter and asymptomatic lesions such as lacunar infarcts. For example, $20 \%$ of healthy elderly patients will present an MRI image with an asymptomatic infarction. Hypertensive small vessel disease (SVD) is a major risk factor for infarction which is associated with minor deficits of physical and cognitive function which are often not realized, especially by elderly patients. ${ }^{13}$

Vascular dementia is a cognitive decline and functional deterioration caused by cerebrovascular disease, which can be caused by hemorrhagic or ischemic strokes and ischemic in the substance alba or sequele of hypotension or hypoxia. Vascular dementia is the second most common cause of dementia (20-25\%) after Alzheimer's disease (60-70\%). The percentage of stroke patients who develop vascular dementia or post-stroke dementia is reported to be around $16-48 \%$. Post-acute ischemic stroke dementia affects the length of survival after acute ischemic stroke and the prognosis. ${ }^{2,6}$

One of the therapies given to vascular dementia to improve cognitive function and the behavior changes that occur is the administration of acetylcholine-esterase inhibitor, which donepezil is widely used and commonly used. In this study donepezil was given to a patient diagnosed with vascular dementia at the Neurology Memory Clinic, Saiful Anwar Hospital Malang. MMSE is a screening instrument to detect and measure the degree of cognitive impairment in patients with cognitive impairments, one of which is vascular dementia. ${ }^{9}$

In the results of this study, there was an increase in the MMSE score in the administration of acetylcholine-esterase inhibitor drugs in patients with vascular dementia during administration and monitoring for 12 months. In the results of increasing MMSE and CDT scores in the sample, the highest increase occurred at 12 months after giving therapy with acetylcholine-esterase inhibitor. This is consistent with previous studies that showed that acetylcholine-esterase inhibitor drug therapy can significantly improve cognitive function in patients with vascular dementia and is also the most tolerable drug given to patients with dementia. However, it should be noted that the many limitations of this study are from the very limited number of research subjects, the lack of supporting data such as laboratory and radiological results causes the study to only conclude that administration of acetylcholine-esterase inhibitors has the best potential to improve cognitive function at month 12. ${ }^{14,15}$

From the results of this study, if one looks at the results of the MMSE, CDT scores, it can be seen that the increase in MMSE scores, CDT scores is quite diverse. In general, the increase in MMSE increased significantly, starting from month 3 with a mean score of 21.33 , then the most significant increase in month 12 with a mean score of 23.33. When observed, patients with low baseline MMSE scores (month 0) showed an unstable increase in MMSE scores and an increase in scores at the end of month 12 could not achieve high scores (24-30). In general, a significant increase in CDT can be seen at month 12 with a mean score of 3.07. When observed in detail, most of the samples achieved a maximum CDT score of 4 at month 12 . However, there were still some samples at month 12 with low CDT scores, namely 1 and 2 where these patients had low baseline CDT scores. This shows that although in general acetylcholine-esterase inhibitor drug therapy improves cognitive function, the degree of cognitive decline also determines the effectiveness of therapy as measured by an increase in MMSE and CDT scores. The earlier cognitive decline can be detected and treated before severe cognitive decline, the better the cognitive improvement. ${ }^{10}$

In the results of this study, it was found that there was an increase in the Barthel Index score in the administration of acetylcholine-esterase inhibitor drugs in patients with vascular dementia during administration and monitoring for 12 months. In the results of the increase in the Barthel Index score in the sample, the highest increase occurred in the 1st month after giving therapy with acetylcholineesterase inhibitor. This is in accordance with previous studies that show acetylcholine-esterase inhibitor drug therapy can improve global function and activity daily living (ADL) in patients with vascular dementia. From the research, it was also found that the optimal dose and significantly improved global function and ADL in patients with vascular dementia was the administration of donepezil at a dose of $10 \mathrm{mg}$ which was better than the dose of $5 \mathrm{mg}$ or placebo. ${ }^{16-21}$

From the results of this study it can be concluded that the administration of acetylcholine-esterase inhibitor drugs has the potential as a therapy that has the potential to improve and maintain cognitive function and improve ADL in patients with vascular dementia where clinically measured by MMSE, CDT can increase in therapy. after 12 months and the Barthel Index increased in the first month after therapy. In addition, the increase in cognitive function and ADL with therapy is influenced by many factors such as the degree of cognitive decline and brain damage that occurs, psychological, and social support. Early detection and management of patients with vascular dementia can provide a better outcome in terms of cognitive function and ADL. Vascular dementia therapy still pays attention to other therapies such as controlling existing vascular risk factors, psychological therapy and non-pharmacotherapy that support holistically and comprehensively the management of vascular dementia patients itself. ${ }^{22}$

The limited number of study subjects and the many confounding factors that we did not evaluate such as patient adherence in taking medication, pharmacological drugs that patients took to control risk factors, support and family motivation were the drawbacks of this study. The results of this study cannot be generalized to all patients with vascular dementia and only apply to 15 patients who were the subjects of this study.

\section{Conclusion}

The administration of acetylcholine-esterase inhibitor therapy has the potential to increase the MMSE and CDT score in vascular dementia patients at month 12, and increase the Barthel Index score in vascular dementia patients at month 1 but with limitations in the form of a limited number of study subjects and the number of confounding factors that were not evaluated. The limited number of study subjects and the number of confounding factors that we did not evaluate meant that the study could 
not be generalized to all patients with vascular dementia and only applied to 15 patients who were the subjects of this study.

\section{Acknowledgement}

The researchers would like to thank Brawijaya University and Dr. Saiful Anwar General Hospital, Malang, East Java, Indonesia for facilitating this research.

\section{Conflict of Interest}

No conflict of interest in this study.

\section{References}

1. World Health Organization. Key Messages The Prevalence Of Dementia Worldwide The Incidence Of Dementia Worldwide The Epidemiology And Impact Of Dementia Current State And Future Trends. 2017 [cited 2019 Dec 27]; Available from: http://www.who.int/mental_health/neurology/dementi a/en/

2. Prince M, Bryce R, Albanese E, Wimo A, Ribeiro W, Ferri CP. The global prevalence of dementia: a systematic review and metaanalysis. Alzheimers Dement [Internet]; 2013 Jan 1 [cited 2018 Feb 27];9(1):63-75.e2. Available from: http://www.ncbi.nlm.nih.gov/pubmed/23305823

3. Pariama AM, Ranimpi YY, Setiawan A. Subjective Well-Being and Healthy Behavior of Elderly With Dementia Alzheimer'S (a Phenomenological Study). MNJ (Malang Neurol Journal); 2020. 6(2):82-7. DOI: https://doi.org/10.21776/ub.mnj.2020.006.02.7

4. Iadecola C. The Pathobiology of Vascular Dementia. Neuron. 2013;80(4):844-66.

5. Iemolo F, Duro G, Rizzo C, Castiglia L, Hachinski V, Caruso C. Pathophysiology of vascular dementia. Immun Ageing [Internet]; 2009 Nov 6 [cited 2018 Feb 25].6(1):13. Available from: http://immunityageing.biomedcentral.com/articles/10. 1186/1742-4933-6-13

6. Samuels MA, Ropper AH. Samuels's Manual of neurologic therapeutics; 2017. 728. ISBN: 978-1-49636031-1

7. Rivarti AW, Herawati L, Hidayati HB. Exercise Prevents Age-Related Memory Decline: the Role of Neurotrophic Factors. MNJ (Malang Neurol Journal); 2020. 6(2):88-94.

DOI: https://doi.org/10.21776/ub.mnj.2020.006.02.8

8. Luttenberger K, Schmiedeberg A, Gräßel E. Activities of daily living in dementia: revalidation of the E-ADL test and suggestions for further development. BMC Psychiatry [Internet]; 2012 Dec 23 [cited 2018 Feb 27];12(1):208. Available from: http://bmcpsychiatry.biomedcentral.com/articles/10.11 86/1471-244X-12-208

9. O’Bryant SE, Humphreys JD, Smith GE, Ivnik RJ, Graff-Radford NR, Petersen RC, et al. Detecting dementia with the mini-mental state examination in highly educated individuals. Arch Neurol [Internet]; 2008 Jul [cited 2018 Feb 27]. 65(7):963-7. Available from: http://www.ncbi.nlm.nih.gov/pubmed/18625866
10. Wang P, Shi L, Zhao Q, Hong Z, Guo Q. Longitudinal changes in clock drawing test (CDT) performance before and after cognitive decline. PLoS One [Internet]. 2014 [cited 2018 Feb 27];9(5):e97873. Available from: http://www.ncbi.nlm.nih.gov/pubmed/24874454

11. Sheehan B. Assessment scales in dementia. Ther Adv Neurol Disord [Internet]; 2012 Nov [cited 2018 Feb 27].5(6):349-58. Available from: http://www.ncbi.nlm.nih.gov/pubmed/23139705

12. Lastri DN, Alwahdy AS. Clinical and Radiologic Approach To Probable Mixed Dementia (Vascular Dementia and Progressive Supranuclear Palsy). MNJ (Malang Neurol Journal); 2020. 6(1):47-50.

DOI: https://doi.org/10.21776/ub.mnj.2020.006.01.10

13. Kalaria RN. Neuropharmacology The pathology and pathophysiology of vascular dementia. Neuropharmacology; 2018. 134:226-39.

DOI: 10.1016/j.neuropharm.2017.12.030

14. Román GC, Salloway S, Black SE, Royall DR, DeCarli C, Weiner MW, et al. Randomized, PlaceboControlled, Clinical Trial of Donepezil in Vascular Dementia. Stroke; 2010. 41(6):1213-21.

DOI: 10.1161/STROKEAHA.109.570077

15. Black S, Román GC, Geldmacher DS, Salloway S, Hecker J, Burns A, et al. Efficacy and tolerability of donepezil in vascular dementia: Positive results of a 24-week, multicenter, international, randomized, placebo-controlled clinical trial. Stroke; 2003. 34(10):2323-30.

DOI: $10.1161 / 01 . S T R .0000091396 .95360 . E 1$

16. Wilkinson D, Doody R, Helme R, Taubman K, Mintzer J, Kertesz A, et al. Donepezil in vascular dementia: A randomized, placebo-controlled study. Neurology; 2003. 61(4):479-86.

DOI: $10.1212 / 01 . w n 1.0000078943 .50032 . f c$

17. Malouf R, Birks J. Donepezil for vascular cognitive impairment. Cochrane Database Syst Rev; 2004. (1). DOI: 10.1002/14651858.CD004395.pub2

18. Baskys A, Hou AC. Vascular dementia: pharmacological treatment approaches and perspectives. Clin Interv Aging; 2007. 2(3):327-35. Avalaible form: https://www.ncbi.nlm.nih.gov/pmc/articles/PMC2685 $259 /$

19. American Psychiatric Association. Task Force on DSM-IV. Diagnostic and statistical manual of mental disorders: DSM-IV-TR. American Psychiatric Association; 2000. 943 p. Avalaible form: https://www.nlm.nih.gov/research/umls/sourcerelease docs/current/DSM4/index.html

20. Sadock BJ, Kaplan HI, Sadock VA. Kaplan \&amp; Sadock's synopsis of psychiatry: Behavioral sciences/clinical psychiatry. Wolter Kluwer/Lippincott Williams \& Wilkins; 2007. 1470 p. ISBN: 13:978-8189960-37-7

21. Bourgeois MS, Hickey EM (Ellen M. Dementia : from diagnosis to management: A functional approach. Psychology Press; 2009. 429 p.

DOI: https://doi.org/10.1080/01924788.2013.816912

22. Vinters H V. Review: Vascular dementia : Clinicopathologic and genetic considerations; 2018. 247-66. DOI: 10.1111/nan.12472 